I acknowledge the help of Mr R J Sergeant and Mr J L Steinberg.

1 Yasu I, Noriyki I, Satoru S. Magnetic removal of alkaline batteries from the stomach. $\mathcal{F}$ Pediatr Surg 1985;20:250-1.

2 Reilly DT. Mercury battery ingestion. Br Med $\mathcal{F}$ 1979; 8559

3 D'Sa EAB, D'Sa AABB. Mercury battery ingestion. Br Med f 1979; 1218.

4 Shabic CL, Feinberg AN. Oesophageal perforation secondary to alkaline battery ingestion. foumal of the American College of Emergency Physicians and University Association for Emergency Medicine 1979;8:360-2.

5 Blatnik DS, Toonhill RJ, Leham RH. Fatal complication from an alkaline battery foreign body in the oesophagus. Ann Otol Rhinol Laryngol 1977;86:611-5.

(Accepted 23 fanuary 1987)

Kent and Sussex Hospital, Tunbridge Wells, Kent TN4 8AT

$P$ FERNANDO, MB, BS, senior house officer in ear, nose, and throat surgery

Correspondence to: Dr P Fernando, Harrogate General Hospital, Harrogate HG2 7ND.

\section{How complete is a total parathyroidectomy in uraemia?}

Hyperparathyroidism is common in chronic renal failure and despite recent medical advances parathyroidectomy is often required. Subtotal parathyroidectomy was performed originally ${ }^{1}$ but because of the risks of recurrent hyperparathyroidism due to hyperplasia of the gland remnant total parathyroidectomy was then recommended, especially in patients destined for long term dialysis. ${ }^{2}$ We report the long term follow up of a group of patients receiving maintenance haemodialysis who were subjected to total parathyroidectomy.

\section{Patients, methods, and results}

Between 1973 and 1976, 12 patients receiving maintenance haemodialysis underwent total parathyroidectomy for severe renal bone disease. Seven long term survivors form the basis of this report. In each of these cases four

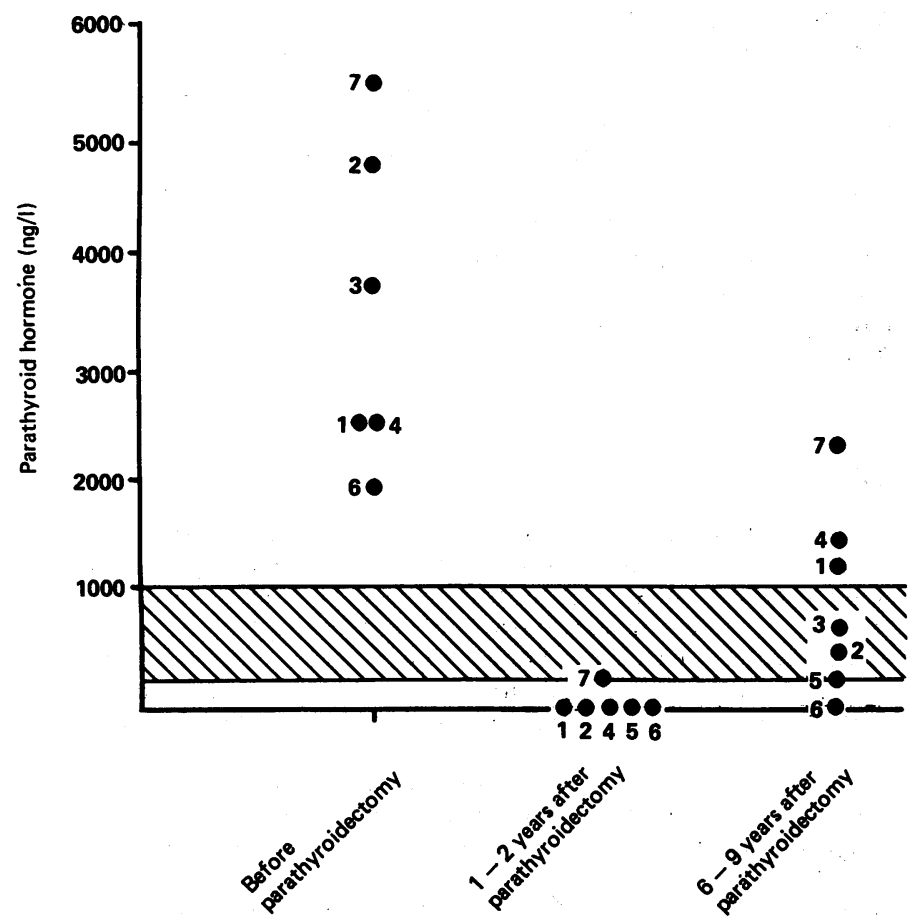

Immunoreactive parathyroid hormone concentrations before total parathyroidectomy and one to nine years afterwards. Hatched area denotes upper and lower limits of normal range. Numbers refer to individual cases. hyperplastic parathyroid glands were removed at operation and confirmed histologically. Immediately postoperatively hypocalcaemia occurred in all patients despite treatment with calcium and vitamin $D$ analogues. Plasma alkaline phosphatase activities, which were raised before operation (mean 387 (SEM 123) KA units/1; normal 30-130), returned to normal within one year in six patients (mean activity at one year 94 (19) KA/l). Plasma hydroxyproline concentrations, which were also high preoperatively (mean $20.5(\mathrm{SEM} \mathrm{7.3}) \mathrm{mg} / \mathrm{l}$; normal $1 \cdot 1-2 \cdot 4$ ), fell more quickly in all patients (mean concentration at one month $4.5(1.0) \mathrm{mg} / \mathrm{l})$. Treatment with calcium and vitamin $\mathrm{D}$ compounds was continued in the long term after operation, the doses being tailored to maintain normal plasma calcium concentrations.

Plasma immunoreactive parathyroid hormone concentrations (measured by radioimmunoassay using Wellcome antibody AS211/32) were obtained preoperatively in six patients and were raised in all (figure). Repeat estimations were obtained in six patients one to two years after total parathyroidectomy. In five patients immunoreactive parathyroid hormone was undetectable but in the sixth the concentration was at the lower limit of normal. Further estimates of immunoreactive parathyroid hormone concentrations were obtained in all patients six to nine years after total parathyroidectomy. At that stage immunoreactive parathyroid hormone was undetectable in only one patient (case 6; figure) and was present in normal concentrations in three patients (cases 2,3, and 5 ), and three patients had frankly raised values (cases 1, 4, and 7). Four patients still required maintenance haemodialysis at final follow up (cases $1,3,4$, and 7); three of these had raised immunoreactive parathyroid hormone concentrations and two had symptomatic bone disease (cases 1 and 7), both of whom had subperiosteal erosions radiologically. Three patients had renal transplants that were functioning well at the time of final follow up (cases 2,5 , and 6 ). In one of these immunoreactive parathyroid hormone was undetectable and two had concentrations in the normal range. None had clinical or radiological evidence of hyperparathyroidism.

\section{Comment}

There were many indications that the removal of four hyperplastic glands in our patients initially resulted in severe hypoparathyroidism. The occurrence of hypocalcaemia despite calcium supplements and vitamin D analogues and the finding of undetectable immunoreactive parathyroid hormone concentrations in five of six patients one to two years after total parathyroidectomy suggest that for some time after total parathyroidectomy there was no effective secretory parathyroid tissue in these patients. These data suggest, however, that detectable immunoreactive parathyroid hormone may be usual six to nine years after total parathyroidectomy and that frankly raised concentrations may also occur. Though some $2 \%$ to $6 \%$ of patients may have supernumerary parathyroid glands, ${ }^{3}$ it is unlikely that hyperplastic supernumerary glands could account for the high incidence of recovery of parathyroid function found in most of our patients. This may be the explanation of our patient (case 7) who had detectable concentrations of immunoreactive parathyroid hormone one year after parathyroidectomy. The likely explanation for the return of parathyroid function in the remaining patients was hyperplasia of small fragments of parathyroid gland left behind at total parathyroidectomy.

Also interesting was that patients who continued with haemodialysis throughout follow up were those in whom concentrations of immunoreactive parathyroid hormone were highest at the end of follow up, whereas those with successful renal transplants had low or undetectable concentrations. This suggests that the uraemic state is the main stimulus to hyperplasia of the remnant parathyroid tissue.

1 Stanbury JW, Lumb GA, Nicholson WF. Elective subtotal parathyroidectomy for renal hyperparathyroidism. Lancet 1960;i:793-8.

$2 \mathrm{Ogg}$ CS. Total parathyroidectomy in the treatment of secondary (renal) hyperparathyroidism. Br Med f 1967;iv:331-4.

3 Wang C, Mahaffey JE, Axelrod L, Perlman JA. Hyperfunctioning supernumerary parathyroid glands. Surg Gynecol Obstet 1979;148:711-4.

(Accepted 19 January 1987)

Department of Nephrology and Transplantation, Royal Free Hospital, London NW3 20G

K FARRINGTON, MD, MRCP, consultant physician

Z VARGHESE, MSC, PHD, top grade biochemist and associate director of renal research unit

M K CHAN, MSC, FIMLS, senior medical laboratory scientific officer

O N FERNANDO, FRCS, consultant surgeon

R A BAILLOD, MB, BS, first assistant

P SWENY, MD, FRCP, senior lecturer and consultant physician

J F MOORHEAD, FRCP, consultant nephrologist and director of department of nephrology and transplantation

Correspondence to: Dr Varghese. 